\title{
A Small Power SMP Based TOPSwitch
}

\author{
Tingjian Zhong, Hongxing Luo \& Wenjin Dai \\ Jiang Xi Vocational \& Technical College of Electricity, Nanchang 330032, China \\ School of information Engineering, Nanchang University, Nanchang 330029, China \\ E-mail: jxdlztj@163.com
}

\begin{abstract}
In designing small power switching mode power supply (SMPS),its functions, tech-parameter and cost should be considered at the same time. TOPSwitch has stronger functions than the discrete components. It is easy and flexible to design SMPS based TOPSwitch and the products always get less cost. SMPS based on UC3842 or UC3843 is compared to the one based TOPSwitch in the paper. Then an actual project used flyback convertor is put forward.
\end{abstract}

Keywords: TOPSwitch, Switching mode power supply, Flyback Digests

\section{Forewords}

Today, TOPSwitch has been usually applied on SMP. But for some matter, people are inclined to use UC3842 or UC3843 as controlling IC when making mention of SMP. In fact, in a small power SMP, especially the SMP as an auxiliary power of system, TOPSwitch should be the best choice and the SMPs based TopSwicth have more vantages compared to the else of based UC3842 or UC3843.

A low power SMP based TOPSwitch which power is less than $200 \mathrm{~W}$ would be used less parts and make circuit simple, volume and weight minishing, cost low.

\section{System designing}

\subsection{Introduction of component}

First, we introduce the three-terminal off-line PWM Switch-TOPSwitch. It is a combination element that integrates a MOSFET power switch with PWM controller. It makes efficiency and stability of SMP higher and at the same time makes the system cost, volume and weight lower. TOPSwitch incorporates all functions necessary for a switched mode control system into a three terminal monolithic IC: power MOSFET, PWM controller, high voltage start up circuit, loop compensation and fault protection circuitry. Power Integrations, Inc. provides several packages for TOPSwitch II .

The SMPs based TOPSwith compared to the else adopted discrete parts have some good points:

(1)Low cost With 15 fewer components, it cuts cost, increases reliability and allows for a smaller and lighter

solution. Source connected tab for low EMI and the gate driver is designed to turn the output MOSFET on at a controlled rate to minimize common-mode EMI. As result, the cost for EMI could be greatly reduced.

(2) High efficiency Compared to discrete MOSFET and controller, TOPSwitch is built-in start-up and its current limit reduce DC losses, cuts switching losses and adopts CMOS controller/gate driver to power consume lower.

(3) Simplifies Design TOPSwitch Integrates PWM Controller with high power MOSFET. It is not demanded R for start-up. Only one external capacitor is needed for compensation, bypass and start-up/auto-restart functions.

(4) Perfect fault-protection function TOPSwitch has auto-restart and cycle by cycle current limiting functions, which can handle both primary and secondary faults. It has on-chip latching thermal shutdown,which can protects the entire system against overload at the same time.

(5) Highly Versatile TOPSwitch can be implemented buck, boost and flyback or forward topology.And it interfaces easily with both opto and primary feedback.

\subsection{Comparison of Project}

Some people always choose forward project, because flyback topology is difficult to design, especially in the case that the transformer has both store energy function and isolated and voltage conversion functions. However we think the flyback topology is better choice when designing off-line term SMP.

The causes are as follows: 
(1) The flyback converter is more flexible to afford multiple voltage outputs, because we can get any expectant voltages by regulating duty ratio(D).Flyback converter outputs voltages can not be restricted by input voltage. There are the proofs as follows:

As shown in Fig.1, when Q is conducted, the current flows throw primary coils and store energy. The rectifier diode suffers negative voltage and the energy is not be transmitted to load R. We can get:

$$
\mathrm{I}_{\mathrm{p}}=\mathrm{V}_{\mathrm{s}} \mathrm{t} / \mathrm{L}_{\mathrm{p}}
$$

where, $\mathrm{i}_{\mathrm{p}}$ is primary current, $\mathrm{V}_{\mathrm{s}}$ is primary voltage, $\mathrm{L}_{\mathrm{p}}$ is the primary inductance.

When $\mathrm{Q}$ is shut off, the magnetic field sharply reduces, the secondary voltage reverses and the diode conducts to charge capacitor $\mathrm{C}$ and transfers current to load, at the same time we can get:

$$
\mathrm{I}_{\mathrm{s}}=\mathrm{I}_{\mathrm{sm}}-\mathrm{V}_{\mathrm{o}} \mathrm{t} / \mathrm{L}_{\mathrm{s}},
$$

Where, $I_{s}$ is the secondary current, $I_{s m}$ is the secondary current maximum, $V_{\mathrm{o}}$ is the output voltage, $L_{s}$ is the secondary inductance.

According to energy conversation law:

$$
\int_{0}^{\text {Ton }} V_{s}^{2} t / L_{p} d t=\int_{\text {Ton }}^{\text {Ton+Toff }} V_{o}\left(I_{s m}-V_{o} t / L_{s} d t\right)
$$

it is easy to get:

$$
\int_{0}^{T o n} V_{s}^{2} t / L_{p} d t=\int_{0}^{T o f f} V_{o}^{2} t / L_{s} d t
$$

Where, $\mathrm{T}_{\text {on }}$ is conduction time, $\mathrm{T}_{\text {off }}$ is shut-off time.

So: $\mathrm{V}_{\mathrm{o}}=\frac{N_{s}}{N_{p}} \mathrm{~V}_{\mathrm{s}} \mathrm{D} /(1-\mathrm{D})$

where $\mathrm{D}=\mathrm{T}_{\text {on }} /\left(\mathrm{T}_{\text {on }}+\mathrm{T}_{\text {off }}\right)$

(2) The flyback transformer in the flyback converter also can be called induct store energy transformer. It has the functions of voltage isolation, storing energy and voltage transform in simultaneity. Energy is transferred by magnetism and disturbance of line can not come into load directly. So the system has better anti-jamming faculty. The rectifier inductors are not necessary, because the transformer is inductor itself. So compared to the othe isolated power convection circuit, the parts of the flyback circuit, especially magnetism parts, can be reduced and the cost is saved too.

\subsection{Design technique}

\subsubsection{Design of high-frequency transformer}

High frequency transformer is important part in energy storing and transferring. Its performances are always the key of a SMP's quality. It affects not only the power supply's efficiency but also EMC of power supply. We must design it elaborately. There are several methods being used as follows

(1) Depressing leakage inductance

(2) Choosing soft ferrite that is sufficed to $100 \mathrm{KHz}$ switch frequency, which has higher resistivity, lower eddy current loss and lower price.

(3) Choosing sharp of EI or EE, whose air gas should be on the mid columniation,which makes convenient to reel coils and flux minimal.

(4) Reeling all kinds of windings one by one, in which primary winding is inner, feedback winding second and secondary winding at last.

(5) Confirming appropriate primary inductance Flyback transformer's primary inductance is essential for its inductor energy transfer-method. It must be proper neither too big nor too small.

Here, a simply method is present to calculate the primary inductance

from

$$
\mathrm{V}_{\mathrm{s}}=\mathrm{L}_{\mathrm{p}} \mathrm{I}_{\mathrm{pm}} / \mathrm{T}_{\text {on }}
$$

and

$$
0.5 \eta \mathrm{I}_{\mathrm{pm}} \mathrm{DTU}_{\mathrm{s}}=\mathrm{P}_{\mathrm{o}}
$$

So the primary inductance : $\mathrm{L}_{\mathrm{p}}=\frac{U_{s}{ }^{2} D^{2} T \eta}{2 P_{o}}$ 
Where, $\mathrm{D}$ is duty ratio, $\mathrm{T}$ is switch period, $\mathrm{P}_{\mathrm{o}}$ is output power and then $\eta$ is efficiency.

In calculation, $\mathrm{I}_{\mathrm{pm}}$ should be magnified $20 \%$.

For switch supply power of this paper, its lowest input voltage is $88 \mathrm{Vdc}$, so order:

$\mathrm{V}_{s}=88 \mathrm{~V}, \mathrm{D}=0.66, \mathrm{~T}=10 \mathrm{us}, \eta=0.7, \mathrm{P}_{\mathrm{o}}=11.3 \mathrm{~W}$, and $\mathrm{I}_{\mathrm{pm}}^{\prime}=1.2 \mathrm{I}_{\mathrm{pm}}$, then $\mathrm{L}_{\mathrm{p}}=870 \mathrm{uH}$ is easy to be gotten.

Design transformer is a course of repeating calculation. The primary inductance needs calculate time and again. For cutting down the works of design, Power Integrations, Inc. offers a set of Excel table to design the transformer.

\subsubsection{Design feedback circuit}

TOPSwitch is a self biased and protected linear control current-to- duty cycle converter with an open drain output. The internal output MOSFET duty cycle linearly decreases with increasing CONTROL pin current as shown in Figure 2. As to control mode, we adopt opto+TL431. TL431 serves as exterior amplifier. The sampling voltage is gotten from R103 and R104 partitioning the output voltage 5V. The sampling voltage compares with the fiducial voltage. when the output voltage exceeds to $5 \mathrm{~V}, \mathrm{I}_{c}$ will increases by optocoupler. Then $\mathrm{D}$ decreases and the output $(5 \mathrm{~V})$ voltage reduces. So the output voltage is steady.

The optocoupler has insulation functions when it works in linear mode. From Fig.2, it is easy to find that Ic must work in 2-6mA. Therefore the optocoupler CTR should be proper too. If CTR is too little, D doesn't increase with the feedback current reducing. If CTR is too big, it is easy to work in nonlinear scope, Consequently, TOPSwitch works abnormally. Commonly, $100 \%-300 \%$ is recommended.

In addition, the apex voltage from leakage inductance could destroy TOP223P.TVS D104 and SRD D103 are used to clamping voltage for protection. Of course,DRC could be adopt too, but at the cost of more power loss.

\section{System assembly \& test result}

The system assembly is shown in Fig.3. We design a sample and make some correlative tests. The test outcomes show the SMP can work steadily in $110 \mathrm{~V}$ or $220 \mathrm{~V}(\mathrm{dc} \& \mathrm{ac})$.Under the rated input voltage- 220VAC, the system efficiency is $70 \%$.Underthe rated load, when input voltage is $85 \mathrm{~V}$ AC $\sim 265 \mathrm{~V}$ AC, the output voltage regulation

ratio is $\mathrm{Sv}=\Delta \mathrm{V} / \mathrm{Vo}=0.5 \%$.Under the rated input voltage, when load is $10 \% \sim 100 \%$ rated load, the load regulation ratio is $\mathrm{Si}=\Delta \mathrm{V} / \mathrm{Vo}=1 \%(\Delta \mathrm{V}$ is the variation of output voltage $)$. It is easy to see that the system has very good work characteristics.

\section{References}

Chuanwen, Ji, and Keyue. M. Smedley. Cross Regulation in Flyback Converters: ANALYTIC MODEL. PESC99.

Gao, Yan, Zhu, Zhongni,Pan, Yulong. (2004). the Analysis and Design of Forward Mode Power Supply Adopted TOPSwitch [J].Power supply technique application, 2004, 4.

Power Integrations, Inc.. TOPSwitch Flyback Transformer Construction Guide[Z]. AN-18. (1996).

Power Integrations, Inc..TOP221-227 TOPSwitch-II Family Three-terminal Off-line PWM Switch[Z].(2001).

Zhang, Zhansong. (1992). High frenqucy switch steady-vlotage supply power[M].Guo Dong science\&technology publishing company.1992, 4.
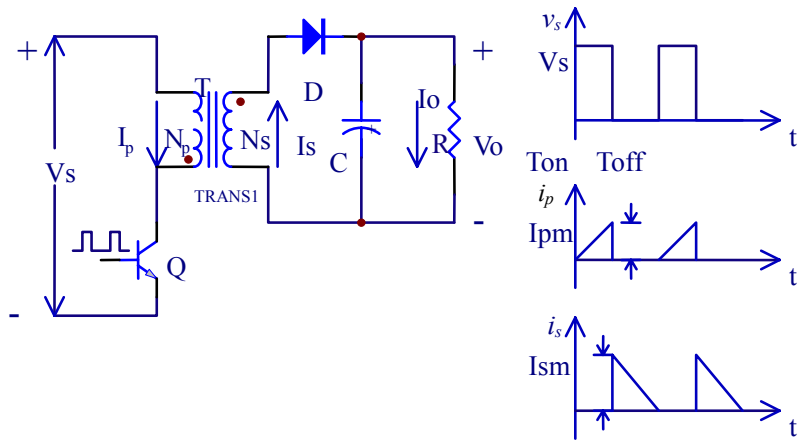

Figure 1. flyback converting-circuit 


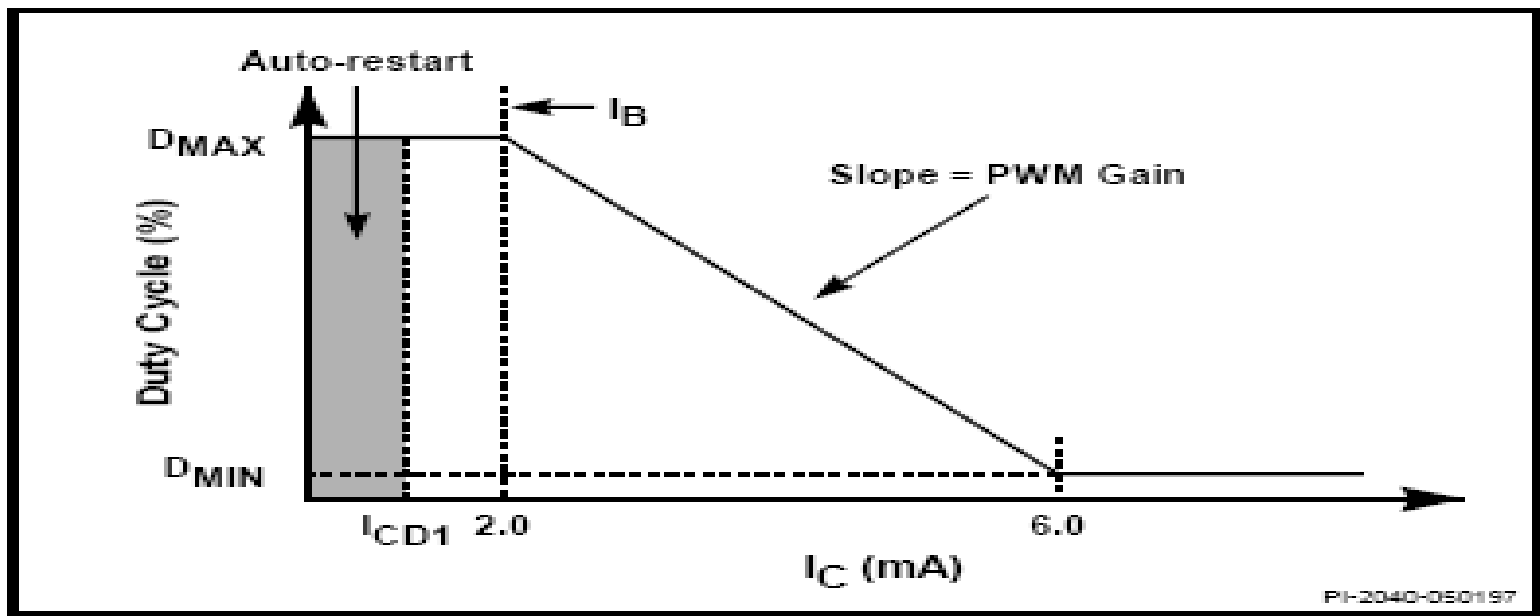

E

Figure 2. Relationship of Duty Cycle to CONTROL Pin Current

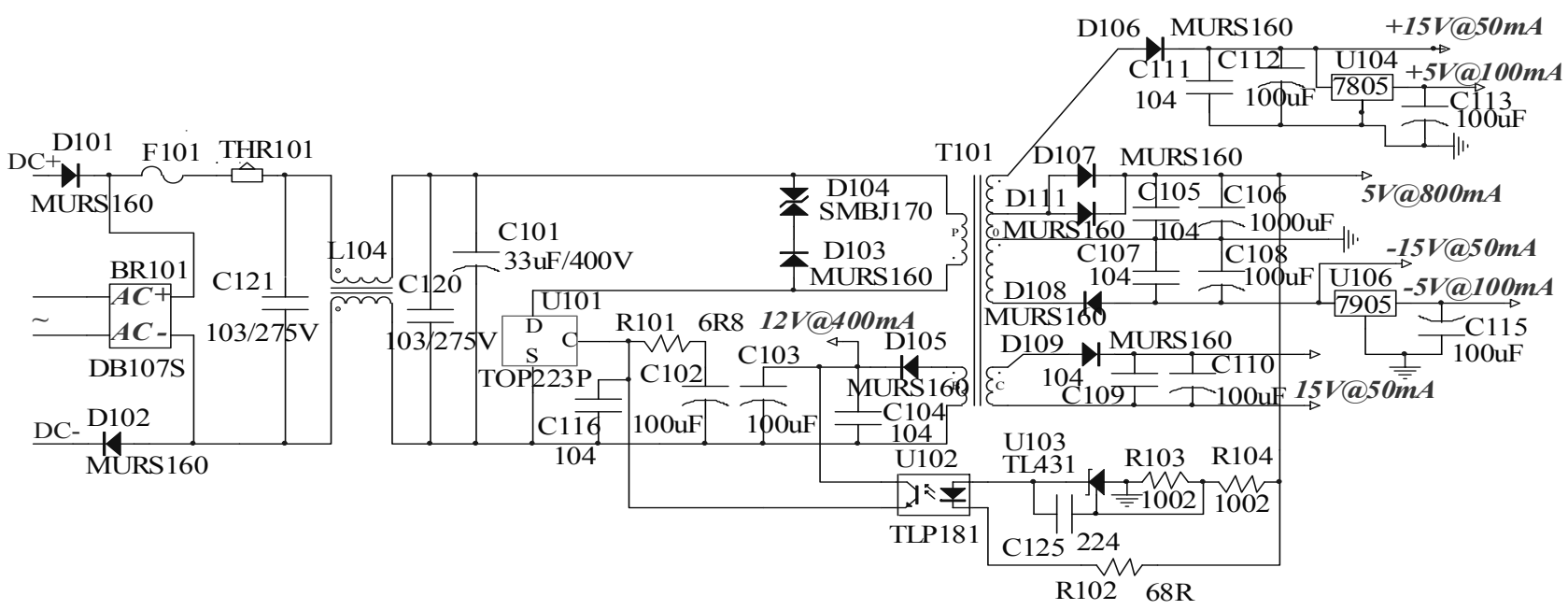

Figure 3. Circuit digram of system 